\title{
Queering generativity and futurity: LGBTQ2IA+ stories of resistance, resurgence, and resilience
}

\author{
By MAY CHAZAN* \& MELISSA BALDWIN*
}

\begin{abstract}
A preoccupation with heteronormative metrics of success in aging leaves many studies of "LGBT aging" focused on the needs, failings, and vulnerabilities of older LGBTQ2IA+ people (i.e. lesbian, gay, bisexual, trans, queer, two-spirit, intersex, asexual, and people of other nonnormative sexual and gender expressions). As a result, LGBTQ2IA+ olders are frequently depicted as isolated, re-closeted, or simply nonexistent. Heeding calls to intervene into such bleak and pathologizing portrayals of queer/ trans aging (e.g. Ramirez-Valles 2016; Sandberg \& Marshall 2017), this article explores diverse subjectivities, nonnormative aging experiences, and their potential intergenerational implications. It draws on stories of queerness, gender, aging, futurity, and social change from 13 LGBTQ2IA+ people ranging in age from 23 to 74, recorded in an intergenerational research-generation workshop held in Nogojiwanong (Peterborough, Canada) in 2018. This article argues that queer and trans stories are crucial to confronting the erasure of LGBTQ2IA+ aging, aiming to extend ongoing efforts within aging studies to queer concepts of successful aging, aging
\end{abstract}

*May Chazan \& Melissa Baldwin, Department of Gender \& Social Justice, Trent University, Peterborough, ON, Canada 
International Journal of Ageing and Later Life

futures, generativity, and intergenerationality. Ultimately, this article aims to complicate constricted understandings of queer/trans aging, instead of depicting LGBTQ2IA+ people aging with connection, pride, learning, and purpose, as well as with struggle and vulnerability.

Keywords: queer, trans, generativity, futures, successful aging, intergenerationality.

\section{Introduction}

Part of it is my own resistance to... the box that I grew up in... [Now] I appreciate that my world is broader and includes all colours of the rainbow. The narrow definitions of what it means to be human don't serve me, and they don't serve the world.

- Dora, 61 years old

Well, I feel a lot safer than I did back then... and I think the word "queer" has opened up so much in my world in terms of the people, the beautiful people that have started circulating into my life, and making it safer to explore parts of myself, and to look at parts of myself that I hadn't before.

- Sandy, 27 years old

Throughout academic and popular discourse, older LGBTQ2IA+ people (including lesbian, gay, bisexual, transgender, queer, two-spirit, intersex, asexual people, and others whose sexual and gender identities do not conform to heterosexual and cisgender norms ${ }^{1}$ ) are frequently depicted as vulnerable, isolated, re-closeted, or simply nonexistent (Brown 2009; Hurd et al. 2020). ${ }^{2}$ In gerontology, a preoccupation with heteronormative vectors of "success" in aging often functions to pathologize older queer and trans lives, with the majority of studies of LGBT aging focused on

\footnotetext{
${ }^{1}$ We use this long acronym, as opposed to LGBT, as a challenge to the erasure of lesser-represented non-normative sexual and gender identities. For more information about these terms, consult https://gbtqia.ucdavis.edu/educated/glossary or www.the519.org/ education-training/glossary

${ }^{2}$ While some scholarship instead highlights the interdependent lives of older LGBTQ2IA+ people with their partners and chosen families (Fredriksen-Goldsen \& Muraco 2010), narratives and studies focused on isolation, invisibility, loneliness, re-closeting, and the failures of these nonetheless prevail (e.g. Butler 2019; Harley et al. 2016; Perone et al. 2020), thus contributing to an ongoing trope of a despairing queer/ trans old age. While we recognize that some older LGBTQ2IA+ people experience loneliness associated with their aging, we problematize the idea of queer aging as necessarily lonely, or dominated by loneliness.
} 
the needs, failings, and vulnerabilities of older LGBTQ2IA+ people (Ramirez-Valles 2016). Though the field of "LGBT aging" has proliferated in recent years, it has been critiqued for a lack of substantive theoretical engagement and for the ways in which dominant aging narratives have continued to reproduce heterosexism (e.g. Sandberg \& Marshall 2017). Analyses that delve into the complexities of aging futures among people of diverse subjectivities remain scarce (Brown 2009; Goltz 2013). Queer and trans people of all ages tend to be "figured by the cultural imagination as being outside of mainstream temporalities and standing in the way of, rather than contributing to, the promise of the future" (Port 2012: 3). Critics do continuously intervene into these bleak portrayals of aging and futurity (e.g. Ophelian \& Florez 2016); yet, there remains a need for more sustained, nuanced, and theoretically engaged understandings of diverse, nonnormative aging experiences and their potential intergenerational implications (Jones 2011; Sandberg \& Marshall 2017).

In the fall of 2018, 24 people from LGBTQ2IA+ communities in Nogojiwanong (Peterborough, Canada), ${ }^{3}$ ranging in age from 23 to 74 , gathered to tell stories of queerness, gender, aging, futurity, and social change, in an intergenerational research-generation workshop. Over 3 days, we shared stories, joked about childhood crushes, envisioned our futures, reveled in moments of joy in our identities, and remembered harmful experiences of homophobia, transphobia, ableism, and racism. With equal parts' wisdom and whimsy, each moment of this workshop was complex and vibrant, defying limiting narratives of queer and trans aging.

In this article, we draw on 13 of the stories generated through this workshop to explore how LGBTQ2IA+ people from two different age cohorts discuss their own sexual and gender identities, how these have changed over their lives, and how they imagine their aging futures. Specifically, we focus on six older storytellers born between 1944 and 1959 and seven younger storytellers born between 1986 and 1995. Intervening in the

\footnotetext{
${ }^{3}$ Nogojiwanong means "the place at the foot of the rapids" in Anishinaabemowin. This is the original name for the region 150 kilometres northeast of the major urban centre of Toronto, which includes the mid-sized city of Peterborough. This territory is governed by Treaty 20 and the Williams Treaties, which settler (non-Indigenous) governments, communities and corporations are neglecting to uphold (Gidigaa Migizi (Williams) 2018; Taylor \& Dokis 2015).
} 
International Journal of Ageing and Later Life

silencing of older LGBTQ2IA+ people, which "render[s] elders invisible in queer theory and queerness invisible in gerontological theory" (Brown 2009: 66), these stories contribute to ongoing conversations in both aging studies and queer studies.

This article responds to calls to better understand diverse later lives, particularly the intricacies of queer and trans aging futures (Cruikshank 2008; Jones 2011; Rajan-Rankin 2018; Sandberg \& Marshall 2017). Linn Sandberg and Barbara L. Marshall (2017), among others, challenge how dominant narratives of "successful aging" are predicated on heteronormative markers of a good life, tying success in later life to heterosexual coupledom and narrow reproductive understandings of generativity. By corollary, these narratives mark many nonnormative lives, LGBTQ2IA+ lives among them, as "failed" - a notion we confront with the complex and rich stories that emerged in our research.

Similarly, we consider the scarcity of work exploring the meanings and practices of intergenerationality among LGBTQ2IA+ communities, including queer conceptions of generativity (Goltz 2013; Hostetler 2009). In tandem with narratives of isolated queer and trans later life, literature on LGBTQ2IA+ aging often assumes a generational divide within queer communities (Cooper Fox 2007; Farrier 2015; Namaste 2014) with little apparent grounding in the lives, perspectives, or practices of LGBTQ2IA+ people (Krainitzki 2016; Rodriguez 2016). We, thus, draw on stories from our research to ask how aspects of generation and age might influence LGBTQ2IA+ experiences; how storytellers from different generations discuss their own aging futures in similar and/or contrasting ways; and whether and how storytellers experience, envision, and practice intergenerational exchange.

With our analysis, articulated through a four-part argument, we aim to extend ongoing scholarship by queering simplistic conceptions of successful aging, aging futures, generativity, and intergenerationality. First, while the stories in this research depict some key differences in how storytellers from different age cohorts describe their experiences, aging, futures, and identities, they, nonetheless, offer more commonality and overlap than they do divergence and, thus, contest assumptions of generational divides. Second, challenging marginalizing and no-future narratives, storytellers across both age cohorts strongly depict their aging as a process of unlearning and healing the internalized shame and 
cis-heteronormative expectations imposed on them in childhood. Third, confronting conceptions of generativity as based on hetero-reproductive relationships, these stories illuminate storytellers' sense of responsibility toward future generations, particularly within their extended families and LGBTQ2IA+ communities. Finally, beyond tropes of intergenerationality as "passing-down" knowledge from older to younger, the intergenerational connections within and among storytellers' lives illuminate deeply held commitments to and practices of learning, advocacy, and care, across ages in all directions.

Overall, then, this article offers complexity to constricted understandings of queer and trans aging, futures, and intergenerationality - shifting from pervasive narratives of queer old-age as isolated, risky, and limited toward stories that reveal connection, pride, learning, and purpose intertwined with struggle and vulnerability. We write for an aging studies audience, adding our work to ongoing interventions into the heteronormativity of successful aging discourses, and expanding and nuancing core gerontological concepts of intergenerationality and generativity.

\section{Methodology: Stories of Resistance, Resilience, and Resurgence}

This article draws on stories recorded at an intergenerational LGBTQ2IA+ storytelling workshop held in October 2018 as part of "Stories of Resistance, Resilience, and Resurgence in Nogojiwanong/Peterborough," a multiyear research project (2016-2020) centring stories from groups that have historically been, and remain, least valued in academic scholarship and aging studies, including women and gender diverse people, people who are racialized, Indigenous peoples, people living with disabilities, and LGBTQ2IA+ people (Chazan 2018; Rajan-Rankin 2018). The project was initiated in 2016 when coauthor May Chazan was approached by a local activist organization to document a "people's history of activism in Peterborough," and build an archive of this work at Trent University. At the time of writing, we had completed three rounds of workshops, in 2016, 2017, and 2018, respectively; each paired with a different community organization, recording a total of 40 stories. Coauthor Melissa Baldwin assisted with organizing and facilitating all three workshops. The 2018 workshop 
International Journal of Ageing and Later Life

was reviewed and approved by the Trent University Research Ethics Review Board in 2018, while the larger project as a whole was approved in 2016.

Critical storytelling methodologies posit storying as crucial decolonial, feminist, and queer forms of knowledge production (e.g. Sium \& Ritskes 2013; Zepeda 2014). This approach - facilitating group storytelling workshops as a form of research - recognizes that contexts and relationships inform how stories are constructed, shared, circulated, and remembered. Through its attention to particularity, complexity, and relationality, storytelling-as-methodology has the potential to challenge dominant narratives and reveal multiple counter-narratives. This project combines storytelling workshops with participatory media-creation methodologies in order to offer participants direct input into how their stories are shared and circulated (e.g. Loe 2013).

The 2018 LGBTQ2IA+ workshop was organized in collaboration with anya gwynne from the Rainbow Youth Program at PARN - Your Community AIDS Resource Network and local queer organizer Ziysah von Bieberstein. Four additional researcher/facilitators from LGBTQ2IA+ communities assisted with the workshop. All participants were invited into the project through existing relationships with members of the research team and were living in the small Canadian city of Peterborough at the time of research. We recorded 16 individual stories, facilitated several roundtable discussions, and invited all participants to create personal "zines" guided by the following core questions:

- Do you want to start by introducing yourself and give us a sense of how you would describe who you are?

- How has your sexuality and/or gender changed at different times in your life, as you have aged?

- Is your gender and/or sexuality connected in some way to resistance or social change, and if so, please tell us about this?

- What is your relationship to this community - Nogojiwanong? What is it like to be you in this place?

- How do you imagine growing older here in Nogojiwanong?

Our team of researcher-facilitators took audio recordings of the interviews and roundtables, as well as observational notes throughout the 
workshop. Researchers worked together with storytellers to create short digital stories with the option to share them on the Aging Activisms website (see www.agingactivisms.org) and in the Trent University Library and Archives (see http://digitalcollections.trentu.ca/collections/stories-resistance-resurgence-and-resilience-nogojiwanong-peterborough).

In preparing to write this article, the authors engaged in an analytic process based on a grounded approach. This involved close readings of interview and roundtable transcripts and researcher-facilitator field notes produced in the 2018 workshop, followed by a combination of reflexive thematic and narrative analysis (see Braun \& Clarke 20204; Reid et al. 2016). Attending to storytellers' different ages and diverse backgrounds and experiences, this analytical process produced several key thematic areas, including generational differences (e.g. shifting sociopolitical contexts through time), intergenerational similarities (e.g. experiencing aging as a process of unlearning multiple internalized oppressions), (queering) generativity and intergenerational connection, shifting experiences of LGBTQ2IA+ identities throughout the lifecourse, responsibilities to the future, and more. The first three of these themes are central to this article. Indeed, to explore age and generational dynamics in this article, we focus our discussion around 13 of the recorded stories, selecting those falling within two broad but distinct age cohorts, and omitting three participants whose ages fall between these cohorts from this paper. The pseudonyms and ages (at the time of recording) of the storytellers of each cohort are as follows:

- Born between 1986 and 1995: Kit 23; Devon 23; Keenan 24; Lilo 24; Bailey 26; Sandy 27; Sam 32

- Born between 1944 and 1959: Cam 59; Dora 61; Mia 66; Marlowe 72; Basil 72; Callee 74

We draw on a small number of participants to offer in-depth, interconnected, and situated experiences and stories of LGBTQ2IA+ aging in one context. These stories are not intended to universalize nonnormative aging experiences, but instead, in their particularity and detail, to offer

\footnotetext{
${ }^{4}$ With gratitude to the reviewer who shared this piece with us, we feel this gentle guide for thematic analysis, while new to us, resonates with the approach we took.
} 
International Journal of Ageing and Later Life

important conceptual interventions into normative and widely circulated narratives. We hold such stories, and the intersubjectivity of their knowledge, as always theoretically generative.

The knowledge produced through this research is informed by the positionality of the authors as well as the activist focus of the research project. Many participants in this research were actively involved in LGBTQ2IA+ groups or community organizing in Peterborough, so our findings do not include the experiences of those who are more private about their sexual and gender identities. While we consider each of these participants as activists (based on our multifaceted understanding of quieter activisms, see Chazan 2018), most would not identify as frontline activists, and most do not have direct ties to formal LGBTQ2IA+ activism. As authors, we are both currently able-bodied, white settlers who had been living and working in Nogojiwanong, on Michi Saagiig Anishinaabeg territory for 5 years at the time of the research. Of different ages (43 and 27, respectively, at the time of the research), we are both part of various queer/trans/activist communities in Peterborough. Our social positions inform own experiences of aging, the questions we ask in our research and, thus, the concepts we have chosen to explore in this article. In addition, our relationships with participants and within the community more generally undoubtedly have informed the knowledge produced in our workshop. Although we did not personally know every participant at the start of the workshop, all were invited through existing relationships, and this allowed for a sense of trust from the outset. We acknowledge, however, that size of this community and our own varying levels of insiderness among participants could result in both intimacy and omissions. Hence, we ask readers to consider our analysis within this important context.

\section{Concepts}

At the intersections of critical aging studies and queer studies, the interpretation we offer in this article engages with - indeed, seeks to extend and queer - concepts of aging futures, generativity, and intergenerationality, while also challenging certain assumptions about queer futurity and LGBTQ2IA+ experience more generally. Our conceptualization of aging as the nonlinear, ever-ongoing processes of change, learning, returning, 
thinking, and acting that happen from birth to death - underpins this analysis while intervening in narratives that equate aging with "old age." Most broadly, this analysis aims to challenge dominant depictions of nonexistent queer futures (Fabbre 2014; Goltz 2013), and heteronormative, ableist, classist, and whitewashed assumptions about "aging well" (Chazan 2019; Sandberg \& Marshall 2017; van Wagenen et al. 2013) that disregard the joys and complexities of coming out, ${ }^{5}$ living, and aging as LGBTQ2IA+ people.

The proliferating field of LGBT aging has largely focused on assessing and responding to the needs, risks, and concerns that older LGBTQ2IA+ people face as they age in a still-heteronormative world (e.g. de Vries \& Croghan 2015; Fredriksen-Goldsen \& de Vries 2019; Sears 2009). This scholarship examines older LGBTQ2IA+ people's experiences with service provision (e.g. Boulé et al. 2020); institutionalized homophobia and transphobia in medical and care contexts (e.g. Kattari \& Hasche 2016; Kia 2016); financial, personal, and social insecurity in the context of queer and trans aging (e.g. Elmet 2016); older LGBTQ2IA+ people's fears of and tendencies toward isolation and loneliness (e.g. Butler 2019; Perone et al. 2020); their resilience in the face of the interlocking oppressions of ageism and cisheteronormativity (e.g. Fredriksen-Goldsen \& de Vries 2019; Moane 2008; Witten 2014); and more. While this work is crucial, much of is still situates older queer and trans people as a population in need (e.g. Boulé et al. 2020; Ramirez-Valles 2016).

A resulting narrative of despair, isolation, and/or vulnerability, thus, arises, in part because many key concepts and theories within aging studies (including, for example, that of "generativity") remain limited by wider heteronormative assumptions (Boulé et al. 2020; Ramirez-Valles 2016). Scholars in this field have worked diligently to seek to better understand and provide for LGBTQ2IA+ aging within existing frameworks and institutional service structures, yet they rarely explore what older LGBTQ2IA+ people and their stories have to offer to revisioning concepts and theories of aging itself, or what LGBTQ2IA+ aging could look like

\footnotetext{
${ }^{5}$ While many storytellers highlighted different ways of "coming out" as an ongoing and ever unfinished process, we join challenges to the linear "coming out" narrative and recognize that "staying in" can also be a resistant and empowering choice (e.g. Hasmanová Marhánková 2019).
} 
International Journal of Ageing and Later Life

when it is freed from ubiquitous heteronormativity. Like Jesus RamirezValles, our "goal is to unmask the ways in which heterosexual dominant norms define what it means to be an older person" (2016: 20-21). We build on this work by attempting to further complicate and nuance mainstream narratives of queer later life and intergenerational queer connection.

Indeed, we heed calls for a more theoretically engaged project of queering aging (Hess 2019; Ramirez-Valles 2016; Sandberg \& Marshall 2017) - which we take to mean challenging and confronting the heteronormativity within mainstream aging studies and gerontological concepts. We draw on Sandberg and Marshall's project of queering/cripping aging futures in the interpretation of our research, which calls into question the ways that "expectations of a good later life and happy aging futures adhere to some bodies and subjectivities over others" (2017: 2; see also Fabbre 2014; Ginsburg \& Rapp 2017; Jones 2011; Rice et al. 2017, for more reflections on liveable crip and/or queer futures). Their work, like ours, contributes to a collective effort to make legible a multiplicity of positive futures - making spaces for lives lived outside of heteronormative, ableist, and otherwise constricting success-versus-failure binaries. Drawing on queer studies, we further interrogate the ways in which queerness (alongside disability, race, and so on) is positioned as antithetical to futurity (Brown 2009; Edelman 2004; Jones 2011; Kafer 2013; Muñoz 2009). We also seek to disrupt the disproportionate focus on young queer lives and challenge assumptions of queer aging as synonymous with frail, isolated, and re-closeted lives (Brown 2009; Goltz 2013; Kia 2016; Witten 2014). ${ }^{6}$ We heed scholarly calls to make multiple, nuanced, nonnormative futurities legible outside of constricting success-versus-failure binaries (Jones 2011; Rice et al. 2017), by offering stories and perspectives shared by a particular group of LGBTQ2IA+ people, which illuminate complex and diverse later lives and highlight queer perspectives on aging futures. Before moving to these stories and perspectives, it is useful to introduce some of the key concepts against and through which we have interpreted this research, and to outline how our interpretations might, thus, extend existing scholarship.

\footnotetext{
${ }^{6}$ There are a small number of powerfully important exceptions to this framing, including the documentary MAJOR!, about trans activist Miss Major Griffin Gacy (Ophelian \& Florez 2016), and the book To survive on this shore: Photographs and interviews with transgender and gender nonconforming adults (Dugan \& Fabbre 2018).
} 
Our analysis engages with and contests mainstream conceptions of generativity as connection to future life through hetero-reproductive relationships. Generative "success," which Sandberg and Marshall (2017) remind us is part and parcel of successful aging discourse, is generally represented through imagery of happy older couples spending leisure time with grandchildren: a capitalist consumerist vision that packages happy heteronormativity up with middle class ideals (see also Chazan 2019; Marshall 2018). As they explain, "depictions of older people with children and grandchildren suggest more than their reproductive success in the present - they are a frequent trope in establishing generativity and the extension of life into the future" (Sandberg \& Marshall 2017: 4). This consistent "imagery of reproductive success" presupposes that it is "(hetero)kinship that makes later life meaningful and positive" (Sandberg \& Marshall 2017: 3). Many scholars have critiqued the notion of generativity as reliant on reproduction, hetero family structures, linear temporalities, and colonial normativity (Chazan 2019; Dinshaw et al. 2007; Grande 2018; Hostetler 2009; Muñoz 2009), and exclusive to "conventional forward-moving narratives of birth, marriage, reproduction and death" (Halberstam 2005: 16). Instead, Jack Halberstam offers "queer time" as a concept of a life trajectory "unscripted by the convention of family, inheritance, and child-rearing" (Halberstam 2005: 16). We also build on Vanessa Fabbre's work on the ways that later life gender transitions expand "notions of queer temporality by drawing attention to growing older in ways that do not follow heteronormative scripts" (2014: 171). Her work, like ours, offers gestures of queer aging as a process of shedding internalized oppressions. We explore storytellers' connections to future generations and articulations of queer generativities, recognizing that few studies offer alternative practices or visions of generativity based on such perspectives (Hostetler 2009).

Furthermore, our analysis aims to challenge assumptions of generational divide or rupture, which are widespread in research and popular discourse on intergenerationality and queerness (Cooper Fox 2007; Farrier 2015; Krainitzki 2016). This perception of a queer generational divide discursively fractures queer intergenerationalities (see Connors 2019; Russell \& Bohan 2005). Indeed, when they are not rendered moot by assumptions of insurmountable gaps, narratives of queer intergenerationality frequently relegate olders to the past and youngers to the future, with 
International Journal of Ageing and Later Life

being neither afforded agency nor connection to one another in the present (Chazan 2018; Chazan \& Macnab 2018; Farrier 2015). Indeed, scholars tend to elide the rich presents and futures of older people, in favor of their pasts, while obscuring younger people's current knowledges and desires for cross-generational relationships. Judith Roof notes the tendency for studies of queer intergenerationality to "ignore intragenerational differences and intergenerational commonalities, and thrive on a paradigm of oppositional change" (1997: 72). Roof suggests that this assumption of generational divide "creates a sense of perpetual debt to the past, rather than a sense of sustained cooperative relations through time" (1997: 72). Relatedly, assumptions of generation gaps in activist writings and feminist scholarship often reinforce divisions which inhibit intergenerational work for change (Binnie \& Klesse 2012; Chazan \& Baldwin 2016). We explore both intergenerational overlaps and dissonances in this article (Adams \& Poteat 2016), seeking a more nuanced understanding of whether and how generation is implicated in these stories of queer and trans aging.

Finally, this analysis seeks to move beyond assumptions of unidirectional passing down of knowledge, which position the old as "archives of political experiences and discursive repositories" and the young as impressionable and inexperienced (Binnie \& Klesse 2012: 580; see also Cooper 2014). Farrier (2015) argues that narratives of queer intergenerationality often focus on passing down the torch of history, most typically limiting intergenerationality within the bounds of conventional familial relations. We examine how intergenerationality is actually discussed and practiced by queer and trans people of different ages. From the stories shared in our research, we highlight some of the specific ways both younger and older storytellers describe their own practices of intergenerational connection.

\section{Generational Differences among Storytellers}

We turn to the findings of this research by exploring two key themes widely present among older storytellers, which contrast the perspectives shared by younger participants. While commonalities were greater than differences between age groups, there are some important distinctions in political context, which shape intergenerational conversations about queerness, and therefore, warrant attention here. First, we note 
generational differences related to sociopolitical context: specifically, the older cohort discussed the ongoing impacts, still felt decades later, of growing up in a time of LGBTQ2IA + repression without protections, supports, or access to knowledge about nonnormative genders and sexualities. Second, in contrast to younger storytellers, they raised significant concerns, fears, and vulnerabilities around growing older as queer people. Before we explore each of these findings in more detail, it is important to highlight the diversity and complexity among older storytellers' (later) lives (see Table 1).

The documented history of LGBTQ2IA+ struggles in Canada (Irving \& Raj 2014; Namaste 2014; Tremblay 2015) indeed offers a trajectory of legal, political, normative, and attitudinal change over the past 70 years. ${ }^{7}$ With drastic shifts in the legal context, as well as in gender roles and expectations, it is not surprising that differences sprouted between the experiences and expressions of storytellers of different ages. Older storytellers discussed the lingering impacts of what it was like to live and work at a time when homosexuality was criminalized. Many also described having no awareness as children of the possibilities of queerness, no representation of nonnormative sexual identities in their lives (at school, in their families, at church, and in the media), and little to no language about gender diversity. While some younger storytellers shared similar stories of lacking access to information, the older cohort experienced longer-lasting and more pervasive internalized shame and oppression.

Like many of the older storytellers, Callee's and Basil's words are illustrative of childhood confusion followed by criminalization in early adulthood. Callee (74, a "Sapphic queer woman") described her early years as a time when the expectations on her were completely out of sync with her body's knowledge of who she was, but she had "no words" or way to make sense of the confusion, restriction, and pain she experienced. She says,

The time I was born... it wasn't like there was just silence, but it was a fortified silence.... So, even though innumerable messages had come to me over time, messages of truth... I had no passageways in my neurons that could bring it up to the conscious mind where thought was possible.

\footnotetext{
${ }^{7}$ Though legal protections of LGBTQ2IA + rights do have positive material effects, we recognize that trends toward "queer inclusion" in settler colonial law are not a simple marker of progress nor a signal of the eradication of homophobia, and that these legal rights are not applied equally to everyone (Dryden \& Lenon 2015).
} 
International Journal of Ageing and Later Life

Table 1. Older storytellers: Diverse (later) lives

The older storytellers described themselves as follows:

Cam (59), a white settler, identified for much of their adult life as a lesbian but, in recent years, embraced identities of queer and genderqueer, and began to use they/ them pronouns. Cam noted that enforced gender expectations had hindered their early explorations of gender nonconformity, and they had instead adopted the available language of tomboy and butch. Cam is leaving a career in the civil service to attend graduate school. They are involved in activist communities in Nogojiwanong and help to lead an LGBTQ2IA+-supportive youth group. They live with their adult child.

Dora (61) recently came to understand herself as demisexual (a term for those who experience sexual attraction only after making a strong emotional connection with someone). A white settler and former teacher (who left teaching as a result of a disability), she is engaged in arts and activist communities in Nogojiwanong. She has never had a long-term partner and described a sense of isolation, not finding the right connections in Nogojiwanong. (Along with her $\mathrm{dog}$ ) she is excitedly embarking on a move to a distant part of the country where she feels a connection to the land and her family history.

Mia (66) moved to Nogojiwanong a few years ago after a traumatic experience with her family. After decades of caring for multiple generations, she decided to live alone. She is in a process of redefining herself and finding new community. She spoke of her decision to marry a white man in her early life as a way to have children and also to resist segregation. Mia is a Black woman who identifies as a lesbian.

Marlowe (72) described being a tomboy as a child and becoming increasingly genderless as she ages. In her early adulthood, she married and had children with a man and was read as heterosexual. She later entered into a longstanding relationship with another woman, her current partner. As a retired journalist and white settler, she continues to actively undertake learning opportunities, activism, community organizing, grandparenting, and youth mentorship.

Basil (72), a white settler, identifies as a gay man. He kept his sexuality hidden for much of his early adulthood for fear of losing his teaching job, remaining closeted in his hometown until recent years. Since the passing of his longstanding partner several years ago, Basil lives alone. He dedicated his career to making schools safe for LGBTQ2IA+ youth and continues his activism post-retirement.

Callee (74) identifies as a Sapphic queer woman, poet, theater artist, activist, white settler, and adventurer in many realms. She has had concerns that being openly identified online as a member of the LGBTQ2IA+ community could negatively impact her living situation. She is actively engaged in spiritual practices and regularly connects with people of all ages through meditation, spoken word, storytelling, and social justice activism. 
In her early adulthood, Callee married a man, whom she described as a good friend, and they had a child whom she expressed great love for. She later realized that she had to come out as a lesbian and live her truth. She divorced her husband, became openly involved with a woman she cared deeply about, and found herself in "exile." As she explained:

At the time, until 1969, homosexual activity was considered a crime, and not until the 1980s was there any protection, in law, in the workplace. So, we're talking about years and years of living in lesbian communities in which we were off the grid completely. We were in exile... and that is hard on the human system.

Several times during the workshop, Callee explained that she is still coming to understand the lasting impacts of these early experiences and to work to be as open about her emotional and sexual orientation as she would like to be.

Like Callee, Basil (72, a gay man) described repressing his sexuality for many years because it felt too impossible or too dangerous to be gay. The impacts of shame, secrecy, and erasure extended over much of his adult life. He reflected on an embodied memory of being labeled a "bad kid," which he later understood to be related to his sexuality:

I still feel my ears burn and my face burn.... You had this burden of shame beginning. And it did follow me for the longest time, and I withdrew into myself. I always realized I was different but I wasn't sure what it was and then, of course, ... I repressed it. I became asexual, as far as I knew, I just didn't want to ... think about it.... The expectations of parents in that time was that you would marry and raise families.

Basil went onto describe the compounding effect of the legal context on him:

I matured, and I began my career as a teacher. But even then, you carried this fear because you could be arbitrarily dismissed from your position without any recourse if you were found to be gay, that was just the way things were. So, you kept this repressed and hidden inside of you, and it really was a release for me then, in the 1980 s.... We gained protection by law for our jobs and this kind of thing, I was able to heave a great sigh of relief.

Basil spent his teaching career working to create safer school spaces for LGBTQ2IA+ students, including developing a safe school policy, but did so with an ongoing sense of caution and secrecy: "It wasn't until that key moment that you were protected by law that you really could do the work 
International Journal of Ageing and Later Life

publicly. And even then, I didn't present myself as a gay teacher, I always presented myself as a teacher who was protective and would work to protect LGBT students, and that was important to me."

While younger storytellers certainly described early experiences of confusion, fear, and internalized oppression (which we will discuss at greater length in the next section), Callee's and Basil's stories illustrate the extended period of time for which they lacked legal protection and support, and the implications of these formative experiences. By contrast, younger storytellers accessed support and knowledge at much younger ages, noting their access to online communities, youth groups, gay-straight alliances, and supportive teachers and social environments.

A second generational difference is that younger storytellers unanimously described feeling safer, more confident, and more whole in their genders/sexualities as they were aging (and particularly as they moved away from their childhood towns, family homes, and/or early school environments). While such positive narratives were shared in certain ways by older storytellers, five out of the six older storytellers also noted elements of challenge or fear associated with aging as queer people. Older participants raised, for instance, the realities that aging will bring them into more acute (and dependent) interactions with medical institutions, care workers, housing services, and social services. In such encounters, older storytellers discussed navigating institutionalized homophobia and transphobia reproduced by policies and mainstream attitudes. Basil, for instance, described the homophobia he and his partner encountered among hospital workers when his partner was ill. Cam noted the need for attention to long-term care, the vulnerability of dependence, and the worry that queer aging might mean going back in the closet if/when they required some form of institutional care. It is noteworthy, however, that while this is evident from the recorded stories as a generational difference - olders noted vulnerabilities associated with queer aging while youngers did not older storytellers did not only discuss aging in these terms. While open about their worries, they also discussed queer aging as being joyful and liberating - indeed, as a complex human experience with a full range of associated emotions. 


\section{Shared Experiences across Generations}

Beyond the differences outlined earlier, the stories in this research offered significant overlap across age. Understanding aging as a process ongoing at all ages, and gender and sexuality as fluid, we asked all storytellers about their own queer aging. We asked how their gender and sexuality had changed over time, and how they imagined aging. Three core themes germinated as common points across ages.

First, storytellers of all ages described their childhood experiences at some length, explaining almost unanimously that they did not, as children, understand their nonnormative genders/sexualities, and that their early experiences, which may have started with joy in exploring gender, involved shaming, repression, and/or restrictive or harmful expectations. Despite radically distinct legal contexts, olders and youngers in approximately equal measure described early memories of not fitting in, having gender norms imposed on them, not having the tools and language to understand their experiences, and feeling afraid, ashamed, or confused. All but two storytellers (one younger and one older) described periods of time in which they actively repressed their nonnormative genders and/or sexualities. The parallels between Cam (59, queer and genderqueer) and Keenan (24, trans man) reflect these commonalities of experience across generations:

Cam: I remember, as a... 6 or 7-year-old, I often played with my brothers without a shirt on, and would go places without my shirt on as well. And I remember being told by strangers that I should have a shirt on, and that it wasn't ok for me to go around without a shirt.... In grade 3 or so, there was a boys' yard and a girls' yard, and you would line up in girls' lines and boys' lines, and I remember wanting there to be a third line.

Keenan: I would be told by my friends that I couldn't do things because I was a girl, and those were things that I didn't really understand. But then hanging out with girls, I was seen as like, the tomboy, right? ... “Okay, you're a tomboy so we'll do tomboy things, or we will try to convince you to do these femme things," and that's when I realized that my gender was a little different. Because during these femme things, it wasn't just uncomfortable, but it was extremely uncomfortable, it was like a... fleeting from my body feeling? Like a tingling from my toes into my hands... a weird sweaty icy feeling, from your hands into your heart? Which I later discovered was a form of dysphoria... I had strangers you know, asking me whether I was a boy or a girl, when I was like 7 and 8. And those aren't questions that you ask strangers, but they felt that they were allowed to ask me them, because I was in this grey area. 
International Journal of Ageing and Later Life

In these stories, the parallels are clear. With 35 years between them, their timelines and early-life contexts (e.g. school rules) differ, yet Cam and Keenan shared experiences of rigid and fearful gender policing. Across ages, storytellers link these kinds of childhood experiences to a sense of deep and complex internalized shame.

Second, in discussions about aging, older and younger storytellers described - with remarkable similarities - queer aging as an ongoing process of coming to understand and unlearn their own internalized oppressions. In different ways, this theme of queer aging as deeply connected to the liberating work of shedding internalized oppressions was evident across 15 out of the 16 stories. Among the olders, Basil (72) described coming out in his hometown at the age of 70, 36 years after marrying a man,

I finally came out in my hometown and that was big. I mean, small town Ontario, they might have thought it, but to actually come out was a great step. And it was very freeing. And that only happened two years ago. So, we are in the process of becoming, as I always say.

Marlowe (72) explicitly discussed recognizing and working through her own internalized homophobia and transphobia in later life, through connections with queer and trans youth. Cam (59) described adopting queer as an identity in recent years, also through connections with youth, as part of unlearning the shame and gender confusion they felt as a child. Dora (61) talked about aging into an understanding of herself as demisexual and, finally, accepting herself outside of the boxes imposed on her. Mia (66) described aging into rejecting the racial segregation she was raised with, as well as later accepting herself as a single lesbian.

These reflections parallel many of the insights offered by younger storytellers on their own aging processes. Kit (23), for instance, described aging as a process of accepting herself as a queer Cree woman, shedding internalized racism and homophobia deeply present in her as a teen. Bailey (26), Sandy (27), and Keenan (24) - all younger Indigenous/ mixed ancestry storytellers - also discussed tackling internalized racism and homophobia as part of growing up, feeling increasingly connected, safe, and whole as they age. Collectively, these reflections offer a complex depiction of queer and trans aging as a process that offers opportunities for unlearning childhood shame and understanding the ways in which 
systems of power are internalized. Queer aging, for these storytellers, is a journey toward rejecting restrictive boxes, honoring truths, and making connections with those on similar journeys. These stories defy suggestions of queer aging as futureless, sad, and isolated.

Finally, and deeply connected to this process of unlearning shame, older and younger storytellers alike experienced aging as a process of honoring other forms of difference. That is, queer aging, for many, was a journey into resisting multiple, intersecting systems of oppression. For instance, Dora (61), Mia (66), and Lilo (24) explained that aging has allowed them to come to terms with the intersections of their nonnormative sexualities and their disability, or race, or both. Kit (23) explained her own aging by discussing her interconnected struggles with gender performance, body image, and internalized racism:

I think I was only able to really feel comfortable with being feminine, and being how I look at all, after I became proud of being Cree and of being a Native woman. Because when I was younger, I died my hair blonde. I wanted to have blue contacts. I was expert at curling my eyelashes, so my eyes didn't look different.... It was only when I had pride in my background that I could feel comfortable with being a woman and, you know, whatever gender I am, because I can see in my face in my features, and I can see when I look at my body, I see an Indigenous woman.

Sam (32) described her own aging as confronting intersections of internalized homophobia and fatphobia:

Going from a skinny kid to a fat kid meant that I wasn't allowed to have a sexuality and that I couldn't perform gender right, because I couldn't be pretty. And it took so much from me, but it also gave me room to become in another direction. If you can't be a Disney princess then you need to be something else, right? ... It's changed so much as I've aged because it's just sort of a learning of how to knit things together.

She went onto describe her shift was from being an asexual evangelical teen (noting the homophobic and shaming sexual messaging embedded in Christianity), to kissing a girl and needing to reconfigure her consciousness, to more recently:

[I am] coming to a place where I'm $32 \ldots$ and maybe what I'm experiencing is fatphobia and oppression that's not actually my problem. Maybe there's something structurally happening here.... Also, to give myself permission and forgiving myself for not girling correctly. 
International Journal of Ageing and Later Life

In her 30s, studying to be a nurse, Sam, thus, described her aging process as a journey toward thoughtfully, actively, and resistantly giving herself and others permission to inhabit their bodies as they are, and to embrace any form of gender and sexuality.

Storytellers from both cohorts described a process of making sense of and unlearning internalized oppressions and shame as they aged. Moreover, they viewed this work of becoming outwardly and acceptingly nonnormative (queer, Indigenous, racialized, disabled, fat, etc.) as a form of resistance to normalizing and violent systems of power. This aging experience offers a strong example of LGBTQ2IA+ intergenerational commonality rather than a frequently assumed generational divide. Far from a marginalizing experience with limited possibility for happy futures, it frames queer aging as a resistant and liberating process of healing from oppression in and through connections with community.

\section{Interconnection and Queer Generativity}

Throughout the stories shared by both younger and older storytellers, as well as in the interactions taking place throughout the workshop, storytellers of all ages emphasized the importance of social connection, particularly a sense of responsibility to relate and offer support across generations. Many also discussed at length both their belief in a version of queer generativity that exists outside of hetero-reproductive relationships, and their ongoing and varied practices of such generativity within and outside of their own families. Their reflections, which were amplified by the connections, resonances, and empathies storytellers made across all ages as they told their stories, critically intervene into assumptions of lonely aging futures and generational divides and offer ways of queering concepts of generativity and intergenerationality.

Storytellers of all ages described a sense of responsibility to support and nurture future (queer) generations, rooted in their own struggles to unlearn shame and oppression as they age. Indeed, many described how their own childhood experiences seeded their desire to make things easier for children and youth now and in the future, to continue to raise awareness, support youth directly, and work for structural change. Many offered detailed accounts of how they are doing this work within their extended families and communities, noting the unique positioning 
of LGBTQ2IA+ people in the work of generativity. For instance, Bailey (23, Cree, and identifying as "gay uncle," nonbinary, and two-spirit), described:

\footnotetext{
What is our responsibility as two-spirit and nonbinary folks within our communities? For me I've a particular interest to what that means with respect to climate change, climate change being something that we all are going to experience and something that affects future generations.... My biggest interest right now is looking at the teachings and seeing what the responsibilities are of people in between the binary... to the earth and water.
}

We heard from Basil (72) that his own experiences of being put down for his sexuality led him to protect and care for LGBTQ2IA+ students:

I would see kids in school being bullied because of their sexuality, and I said, "there's one thing I can do, I can keep my classroom and hallway a safe place for kids who are gay, who are different." So, I would make it a point to be out in the hall, and if I heard homophobic sneers and snipes, I would address it and point out the need for people to feel safe. And it was a great sense of relief that you were able to do something positive in the lives of another younger generation coming through.

In the context of her own family, Sandy (27, a queer woman of mixed Anishinaabe and Irish ancestry) similarly described the importance of intergenerational connection:

My grandparents, oh gosh, are amazing. So, I came out and they of course loved me and held me. Then my young cousin came out as pansexual a few years later. And they're like, "Oh, that's cool. I don't know what that is." They went on Wikipedia, talking to me on the phone, and they're like, "And then we found all these other cool terms! What does this mean?" But just so loving.... So, I feel I have a responsibility to carry that forward in spaces where maybe other folks have not felt that love and acceptance.

Collectively, these storytellers offer ongoing and varied impressions of queer generativity that extend well beyond hetero-reproductive relationships. They suggest a concept of queer generativity rooted in a set of responsibilities that come with aging as and into queer and trans people, responsibilities oriented toward future LGTBQ2IA+ generations, and, indeed, all life through relationships within extended families, communities, and through varied social change work. Their reflections, which were amplified by the connections, resonances, and empathies formed during 
International Journal of Ageing and Later Life

the workshop, critically intervene into assumptions of lonely aging futures and generational divides.

Connection and community-making resonate throughout stories of queer and trans aging, even when also describing isolation. Four out of the six older storytellers, three of which were living alone, described their rich social networks, their connections to youth, and their ongoing practice and connection within art, activist, community organizing, and learning communities. Three of the olders described experiences of loneliness, loss, or unbelonging in their later lives, but each paired these sentiments with descriptions of their ongoing work in community, plans to foster new connections, and undertake new learning.

Discussions of intergenerational connection among both cohorts significantly challenged notions of intergenerationality as a unidirectional passing down of knowledge, care, and advocacy from older to younger. Rather, participants depicted multidirectional relationships of care, learning, and advocacy throughout their queer lives and networks. Cam (59), for instance, explained that it was only in their recent work with youth that they came to gain language and concepts to help make sense of their own gender:

It wasn't until quite a bit later, I was doing stuff with youth... They did have language for this, and they did feel more able to be themselves. I learned a lot from the youth. It's from them that I learned to accept the word "queer." ... I had known about trans stuff before but [working with youth] has given me that environment to sort of work through that stuff, because it's been a long time, that I have, like, pressed down that part of me.

Similarly, Marlowe (72) explained that her process of unlearning oppressions - of learning to change her views through listening and recognizing homophobia and transphobia - was catalyzed by the knowledges shared by youth when she volunteered at an LGBTQ2IA+ summer camp. In a further flip of generational scripts, Sam (32) spoke at length about her desire to become a nurse as a way of offering something back to the community, of wanting to be there in the more vulnerable moments to advocate and care for older people, especially LQBTQ2IA+ olders navigating the medical system as they come to the end of their lives. In a tender exchange, Basil later commented: "Well, certainly I look forward as I edge forward in my life journey, to know that there will be a nurse who cares." Sam 
responded strongly and lovingly expressing the importance of intergenerational advocacy and care from younger to older: "But this is the thing though, [Basil]. I'm doing it for you."

These stories, these interactions, and the relationships they illuminate offer a nascent concept of queer generativity and intergenerationality as a sense of responsibility and connection across generations. These stories vividly paint intergenerational connection as multidirectional learning, care, advocacy, and reciprocal relationship-building. This connection, held in these stories as precious and hallowed, is rooted in shared embodied knowledge of how homophobic and transphobic systems continue to impact people all along the lifecourse, and in a desire to be part of continuing to dismantle these systems.

\section{Conclusions}

The stories woven through this article challenge dominant concepts of "successful aging," contributing complexity and lived experience to ongoing efforts to queer aging futures. As Sandberg and Marshall (2017) explain:

Queering aging futures entails thinking differently about life courses-asking what lives are understood as desirable to live and thrive well into old age-but also interrogating how desirable old age is problematically framed by the exclusionary discourses of successful aging. (p. 7)

Our analysis responds to these exclusionary discourses as well as to their piercing questions: "Whose lives are worth preserving for old age? Whose aging is understood as livable aging?" (Sandberg \& Marshall 2017). Heeding their call - "to begin to address these questions will require that a multiplicity of futures become visible" - we centered 13 stories offered by LGBTQ2IA+ storytellers of different ages. This analysis is an effort to make visible a multiplicity of queer and trans aging futures. But beyond simply adding different voices into aging studies, the knowledges contained in these stories offer important epistemological interventions (Chazan 2019). Our analysis seeks to bring these often-omitted knowledges to bear on key aging studies concepts, thereby extending the epistemological and conceptual contours of this field. 
International Journal of Ageing and Later Life

Most evidently, these stories put pressure on binary assumptions of success-versus-failure embedded within dominant successful aging narratives (Sandberg \& Marshall 2017). Storytellers do not idealistically obscure neither their fears of queer and trans aging nor the very real homophobia and transphobia that make this aging more precarious (Witten 2014). Rather, they share their varied experiences as queer and trans people growing older, including their sense of futures enwrapped with both fear and joy, success and decline, and isolation and connection. These are not superficially glossy stories, but rather stories of joy, hope, relationship, struggle, and growth into ever-budding self-acceptance.

Part of the task of queering aging futures is calling into question the success-failure binary and heteronormative, ableist, and classist societal ideals. Another part is unpacking the expectations that futurity (and thus happiness in old-age) is inextricably bound to a particular conception of generativity, that is, connection to future offspring (Hostetler 2009). The stories shared here offer pertinent conceptual interventions in their caring interactions with one another and their expressions of responsibility to future generations. These storytellers queer hetero-reproductive understandings of generativity, instead describing responsibilities to future life within and outside of reproductive kinship (Chazan 2019). Furthermore, these storytellers depict significant commonality of experience across age and detail accounts of cross-generational relationships. In sharing these visions, experiences, and practices, they challenge dominant perceptions of generational divide within LGBTQ2IA+ communities (Farrier 2015). In many ways, their stories honor the knowledges they held as children, their learning as they age, and their commitments to sharing wisdom, support, and advocacy across generations. These stories contest well-trodden aging themes of positive old-age, featuring happy couples passing the torch to their grandchildren, demonstrating a richer array of later-life experiences and intergenerational connections.

Remarkably, the storytellers, all living in relation to overlapping systems of oppression, collectively illuminated how the aging process is a liberating one of unlearning oppression(s), shedding internalized shame, and supporting future generations. Thus, it is in their ongoing relations to these systems of oppression that the knowledges the storytellers hold most fundamentally challenge dominant ways of thinking about aging and futurity. Without denying the pains, loneliness, and fears of aging, 
storytellers simultaneously express their processes of, as Basil says, "always becoming" themselves, resisting the binary expectations of gender, sex, sexuality, and aging imposed on them across their lives. Their resistant revisioning of LGBTQ2IA+ aging, which bears strong connections to their pasts, is also very much oriented toward making new possible futures for themselves, for each other, and for future generations.

\section{Corresponding Author}

May Chazan, Department of Gender \& Social Justice, Lady Eaton College N114, Trent University, 1600 West Bank Drive, Peterborough, ON, K9L 0G2, Canada. Email: maychazan@trentu.ca

\section{References}

Adams, M. A. \& Poteat, T. (2016). Zami Nobla: Preserving history and fostering wellness in Black lesbians. Generations 40(2): 80-82.

Binnie, J. \& Klesse, C. (2012). The politics of age, temporality, and intergenerationality in transnational lesbian, gay, bisexual, transgender, and queer activist networks. Sociology 47(3): 580-595.

Boulé, J., Wilson, K., Kortes-Miller, K. \& Stinchcombe, A. (2020). “We live in a wonderful country, Canada, but...": Perspectives from older LGBTQ Ontarians on visibility, connection, and power in care and community. The International Journal of Aging and Human Development 91(3): 235-252. doi: 10.1177/0091415019857060

Braun, V. \& Clarke, V. (2020). One size fits all? What counts as quality practice in (reflexive) thematic analysis? Qualitative Research in Psychology 18(3): 328-352. doi: 10.1080/14780887.2020.1769238

Brown, M. T. (2009). LGBT aging and rhetorical silence. Sexuality Research $\mathcal{E}$ Social Policy 6(4): 65-78.

Butler, S. S. (2019). Social networks and social isolation among LGBT older adults. In L. W. Kaye \& C. Springer (eds.), Social Isolation of Older Adults: Strategies to Bolster Health and Well-Being (pp. 181-196). New York: Springer.

Chazan, M. (2018). Introduction: Amplifying activisms. In M. Chazan, M. Baldwin \& P. Evans (eds.), Unsettling Activisms: Critical Interventions on Aging, Gender, and Social Change (pp. 1-20). Toronto, ON: Women's Press. 
International Journal of Ageing and Later Life

Chazan, M. (2019). Unsettling aging futures: Challenging colonial-normativity in aging studies. International Journal of Ageing and Later Life 14(1): 91-119. doi: $10.3384 /$ ijal.1652-8670.19454

Chazan, M. \& Baldwin, M. (2016). Understanding the complexities of contemporary feminist activism: How the lives of older women activists contest the waves narrative. Feminist Formations 74(3): 70-94.

Chazan, M. \& Macnab, M. (2018). Doing the feminist intergenerational mic: Digital storytelling methodology as social change praxis. FORUM: Qualitative Social Research 19(2): 1-19. Available on www.qualitative-research.net/index.php/fqs/article/view/2949/4210 (Accessed: December 16, 2019).

Connors, S. W. K. (2019). Intergenerational space-holding within Lesbian, gay, bisexual, transgender, and other gender \& sexual minority communities. Community Engagement Student Work, 26. Available on https://scholarworks.merrimack.edu/soe_student_ce/26 (Accessed: June 7, 2020).

Cooper, D. (2014). Generations of activism and queer time. JOTWELL (January 22, 2014). Available on http://equality.iotwell.com/generations-of-activism-and-queer-time/ (Accessed: June 20, 2019).

Cooper Fox, R. (2007). Gay grows up: An interpretive study on aging metaphors and queer identity. Journal of Homosexuality 52(3/4): 33-61.

Cruikshank, M. (2008). Aging and identity politics. Journal of Aging Studies 22: 147-151.

de Vries, B. \& Croghan, C. (2015). Community-Based Research on LGBT Aging. New York: Routledge.

Dinshaw, C., Edelman, L., Ferguson, R. A., Freccero, C., Freeman, E., Halberstam, J., Jagose, A., Nealon, C. S. \& Hoang Nguyen, T. (2007). Theorizing queer temporalities: A roundtable discussion. GLQ 13(2-3): 177-195.

Dryden, O. H. \& Lenon, S. (2015). Disrupting Queer Inclusion: Canadian Homonationalisms and the Politics of Belonging. Vancouver: UBC Press.

Dugan, J. T. \& Fabbre, V. (2018). To Survive on this Shore: Photographs and Interviews with Transgender and Gender Nonconforming Older Adults. Heidelberg: Kehrer Verlag.

Edelman, L. (2004). No Future: Queer Theory and the Death Drive. Durham, NC: Duke University Press.

Elmet, C. A. (2016). Social, economic, and health disparities among LGBT older adults. Generations 40(2): 16-22. 
Fabbre, V. D. (2014). Gender transitions in later life: The significance of time in queer aging. Journal of Gerontological Social Work 57(2-4): 161-175.

Farrier, S. (2015). Playing with time: Gay intergenerational performance work and the productive possibilities of queer temporalities. Journal of Homosexuality 62: 1398-1418.

Fredriksen-Goldsen, K. \& de Vries, B. (2019). Global aging with pride: International perspectives on LGBT aging. International Journal of Aging and Human Development 88(4): 315-324.

Fredriksen-Goldsen, K. \& Muraco, A. (2010). Aging and sexual orientation: A 25-year review of the literature. Research on Aging 32(3): 372-413.

Gidigaa Migizi (Williams, D.). (2018). Michi Saagiig Nishnaabeg: This is Our Territory. Winnipeg, MB: ARP Books.

Ginsburg, F. \& Rapp, R. (2017). Making accessible futures: From the capitol crawl to \#cripthevote. Cardozo Law Review 39: 699-718.

Goltz, D. B. (2013). It gets better: Queer futures, critical frustrations, and radical potentials. Critical Studies in Media Communication 30(2): 135-151.

Grande, S. (2018). Aging, precarity, and the struggle for Indigenous elsewheres. International Journal of Qualitative Studies in Education 31(3): 168-176.

Halberstam, J. (2005). In a Queer Time and Place: Transgender Bodies, Subcultural Lives. New York: NYU Press.

Harley, D. A., Gassaway, L. \& Dunkley, L. (2016). Isolation, socialization, recreation, and inclusion of LGBT elders. In D. Harley \& P. Teaster (eds.), Handbook of LGBT Elders (pp. 563-581). New York: Springer. doi: 10.1007/978-3-319-03623-6_30

Hasmanová Marhánková, J. (2019). Places of (in)visibility, LGB aging and the (im)possibilities of coming out to others. Journal of Aging Studies 48: 9-16.

Hess, L. M. (2019). Queer Aging in North American fiction. London: Palgrave Macmillan.

Hostetler, A. J. (2009). Generativity and time in gay men's life stories. In P. L. Hammack \& B. Cohler (eds.), The Story of Sexual Identity: Narrative Perspectives on the Gay and Lesbian Life Course (pp. 397-424). Oxford: Oxford University Press.

Hurd, L., Mahal, R., Ng, S. \& Kanagasingam, D. (2020). From invisible to extraordinary: Representations of older LGBTQ persons in Canadian print and online news media. Journal of Aging Studies 55. doi: 10.1016/ j.jaging.2020.100877 
International Journal of Ageing and Later Life

Irving, D. \& Raj, R. (eds.). (2014). Trans Activism in Canada: A reader. Toronto, ON: Canadian Scholars' Press.

Jones, R. L. (2011). Imagining bisexual futures: Positive, non-normative later life. Journal of Bisexuality 11(2/3): 245-270.

Kafer, A. (2013). Feminist, Queer, Crip. Bloomington: Indiana University Press.

Kattari, S. K. \& Hasche, L. (2016). Differences across age groups in transgender and gender non-conforming people's experiences of health care discrimination, harassment, and victimization. Journal of Aging and Health 28(2): 285-306.

Kia, H. (2016). Hypervisibility: Toward a conceptualization of LGBTQ aging. Sexuality Research and Social Policy 13: 46-57.

Krainitzki, E. (2016). “Older-wiser-lesbians" and "baby-dykes": Mediating age and generation in New Queer Cinema. Feminist media studies 16(4): 631-647.

Loe, M. (2013). The digital life history project: Intergenerational collaborative research. Gerontology E Geriatrics Education 34: 26-42.

Marshall, B. L. (2018). Happily ever after? "Successful ageing" and the heterosexual imaginary. European Journal of Cultural Studies 21(3): 363-381.

Moane, G. (2008). Building strength through challenging homophobia: Liberation workshops with younger and midlife Irish Lesbians. Journal of Gay $\mathcal{E}$ Lesbian Social Services 20(1-2): 129-145. doi: $10.1080 / 10538720802179096$

Muñoz, J. E. (2009). Cruising Utopia: The Then and There of Queer Futurity. New York: NYU Press.

Namaste, V. (2014). "We paved the way for whatever tolerance they have in their lives": An interview with Michelle DeVille, "the first door bitch in Montreal." In D. Irving \& R. Raj (eds.), Trans Activism in Canada: A reader (pp. 19-26). Toronto, ON: Canadian Scholars' Press.

Ophelian, A. (producer/director) \& Florez, S. (co-producer/editor). (2016). Major! [Documentary film]. What Do We Want Films with Floating Ophelia Productions. Available on www.missmajorfilm.com (Accessed: August 6, 2021).

Perone, A. K., Ingersoll-Dayton, B. \& Watkins-Dukhie, K. (2020). Social isolation loneliness among LGBT older adults: Lessons learned from a pilot friendly caller program. Clinical Social Work Journal 48: 126-139. doi: 10.1007/s10615-019-00738-8

Port, C. (2012). No future?: Aging, temporality, history, and reverse chronologies. Occasion: Interdisciplinary Studies in the Humanities 4. Available 
on https:/ / arcade.stanford.edu/sites/default/files/article_pdfs / OCCASION_v04_Port_053112_0.pdf (Accessed: December 16, 2019).

Rajan-Rankin, S. (2018). Race, embodiment and later life: Re-animating aging bodies of color. Journal of Aging Studies 45: 32-38.

Ramirez-Valles, J. (2016). Queer Aging: The Gayby Boomers and a New Frontier for Gerontology. Oxford: Oxford University Press.

Reid, C., Greaves, L. \& Kirby, S. (2016). Experience Research Social Change: Critical Methods, Third Edition. Toronto ON: University of Toronto Press.

Rice, C., Chandler, E., Rinaldi, J., Changfoot, N., Liddiard, K., Mykitiuk, R. \& Mündel, I. (2017). Imagining disability futurities. Hypatia 32(2): 1-17.

Rodriguez, V. N. (2016). “I own my T!”: The experience of older transgender people of color regarding personal identity, systems of support, and desires for the future. [Unpublished PhD dissertation]. Smith College. Available on https://scholarworks.smith.edu/theses/1740 (Accessed: June 20, 2019).

Roof, J. (1997). Generational difficulties; or, the fear of a barren history. In D. Looser \& E. A. Kaplan (eds.), Generations: Academic Feminists in Dialogue (pp. 69-87). Minneapolis, MN: University of Minnesota Press.

Russell,G. M. \& Bohan, J.S. (2005). The gay generation gap: Communicating across the LGBT generational divide. IGLSS 8(1): 1-8.

Sandberg, L. \& Marshall, B. L. (2017). Queering aging futures. Societies 7(3): 1-11.

Sears, J. T. (2009). Growing Older: Perspectives on LGBT Aging. London: Routledge.

Sium, A. \& Ritskes, E. (2013). Speaking truth to power: Indigenous storytelling as an act of living resistance. Decolonization: Indigeneity, Education, \& Society 2: i-x.

Taylor, A. \& Dokis, M. (2015). Oshkiigmong: A place where I belong, the tory of the Michi Saagiig (Mississauga) of Curve Lake First Nation. [Documentary film]. Curve Lake First Nation.

Tremblay, M. (ed.). (2015). Queer Mobilizations: Social Movement Activism and Canadian Public Policy. Vancouver, BC: UBC Press.

Van Wagenen, A., Driskell, J. \& Bradford, J. (2013). "I'm still raring to go": Successful aging among lesbian, gay, bisexual, and transgender older adults. Journal of Aging Studies 27: 1-14. 
International Journal of Ageing and Later Life

Witten, T. M. (2014). It's not all darkness: Robustness, resilience, and successful transgender aging. LGBT Health 1(1): 24-33.

Zepeda, S. J. (2014). Queer Xicana Indígena cultural production: Remembering through oral and visual storytelling. Decolonization: Indigeneity, Education, \& Society 3: 119-141. 